\title{
Anchoring effects in the development of false childhood memories
}

\author{
KimberLey A. WADE \\ University of Warwick, Coventry, England \\ MARYANNe GARRY \\ Victoria University of Wellington, Wellington, New Zealand \\ Robert A. NASH \\ University of Warwick, Coventry, England \\ AND \\ DAVID N. HARPER \\ Victoria University of Wellington, Wellington, New Zealand
}

\begin{abstract}
When people receive descriptions or doctored photos of events that never happened, they often come to remember those events. But if people receive both a description and a doctored photo, does the order in which they receive the information matter? We asked people to consider a description and a doctored photograph of a childhood hot air balloon ride, and we varied which medium they saw first. People who saw a description first reported more false images and memories than did people who saw a photo first, a result that fits with an anchoring account of false childhood memories.
\end{abstract}

Many self-help books promote techniques for remembering childhood experiences, claiming that recall will help to validate traumatic events. Some books suggest talking to family members to trigger lost memories; other books urge readers to review childhood photos (McKinnon, 2008; Sanderson, 2006; Whitfield, 1995). But repeatedly thinking about false childhood descriptions or reviewing false childhood photos can cause people to remember experiences that never happened (Loftus, 2004; Loftus \& Pickrell, 1995; Wade, Garry, Read, \& Lindsay, 2002). Together, these findings warrant an attempt to understand the role of different types of information - such as written evidence and photos - in the development of false childhood memories. In this article, we ask what happens to memory when people encounter written and then photographic evidence of a false event and what happens when the order is reversed.

According to the source-monitoring framework, we create false memories in much the same way that we identify true memories. Remembering is an act of evaluation and classification: First, people evaluate their mental products along various dimensions; second, they classify these products as resulting from genuine experience or from mental activity, such as imagination, dreams, or fantasy (Johnson, Hashtroudi, \& Lindsay, 1993; Lindsay, 2008). Although people usually classify their mental experi- ences quickly and without awareness, when the process goes wrong, people incorrectly decide that a false autobiographical experience was real.

To study false autobiographical memories, scientists often use a variation of the memory implantation technique (Loftus \& Pickrell, 1995; Wade et al., 2007). In this technique, people receive evidence-ostensibly provided by a family member - of specific childhood experiences. The twist is that one of the experiences is false. Across 13 studies, $37 \%{ }^{1}$ of people, on average, reported images or memories for a range of false events, such as being hospitalized overnight, being attacked by an animal, winning a prize in a contest, or playing a prank on a teacher (Desjardins \& Scoboria, 2007; Hyman, Husband, \& Billings, 1995; Ost, Foster, Costall, \& Bull, 2005; Porter, Yuille, \& Lehman, 1999). This literature shows that people can generate a variety of rich, false autobiographical memories.

In the most common variant of the implantation technique, the evidence for the false event is a written description. More recent research shows that photographic evidence can produce similar effects (see Garry \& Gerrie, 2005 , for a review). Still other research shows that combining a false description with a genuine photo leads to more false memories than does a false description alone (Lindsay, Hagen, Read, Wade, \& Garry, 2004). What we do not know is the effect of giving people both written and

K.A.Wade, k.a.wade@warwick.ac.uk 
photographic evidence, but at different times. To address this question, we asked adults to consider a false description and a doctored photograph of a childhood hot air balloon ride and varied which medium they saw first.

\section{Anchoring}

Research on anchoring leads us to expect that people who encounter a description first (hereafter, description-first subjects) should report more false memories than should people who encounter a photo first (hereafter, photo-first subjects). When people make decisions on the basis of multiple sources of evidence, the information they acquire early in the process is often more influential than the information they acquire later (Peterson \& DuCharme, 1967). For example, Hart's (1995, Experiment 2) mock jurors listened to evidence about a traffic accident. The evidence was presented in various ways, biased in favor of either the defendant's guilt or innocence. Most important, jurors exposed to a guilty followed by a not-guilty bias more often produced guilty verdicts than did jurors exposed to a notguilty followed by a guilty bias. Presumably, the early evidence had more weight on the jurors' decisions.

Why are our judgments biased toward information we encounter first? One explanation is that early information anchors and shapes the way we gather and interpret subsequent information. Indeed, people typically make an initial judgment on the basis of the first piece of evidence they receive, then update that judgment by considering the implications of each new piece of information (Carlson \& Russo, 2001). Because source monitoring is a judgment process, we might expect to find anchoring effects in the development of false memories: The first piece of evidence people receive should influence their source monitoring more than should the second piece of evidence. If so, research suggests that when the first piece of evidence is a written description, people should be especially prone to developing false memories.

Garry and Wade (2005) found that people who read a description of a false childhood balloon ride were more likely to cultivate false images and memories, and to speculate about the false event, than were people who saw a doctored photograph. Descriptions, Garry and Wade hypothesized, better support activities known to produce false memories: They give free rein to the imagination and allow more speculation and infusion of personal knowledge into people's images and memories (Lyle \& Johnson, 2006; Sharman \& Scoboria, 2009). Taken together, then, research on anchoring effects and on false autobiographical memories suggests that description-first people would report more false images and memories than would photofirst people.

\section{Consistency}

Other research suggesting that the consistency of details across the pieces of evidence is paramount leads us to predict the opposite pattern of results. Consistency is the extent to which separate pieces of evidence fit together. For instance, when pairs of adults described a long-ago shared experience and then evaluated the accuracy of each other's memory, they used the consistencies (or inconsis- tencies) between their own and their partner's statements to justify their accuracy judgments (Ross, Buehler, \& Karr, 1998).

If people rely on consistency to distinguish between real and false memories, encountering a description of the balloon ride first should give their imagination free rein, allowing them to imagine fellow balloon riders, balloon styles, and so on. But later, when they encounter the photo of the balloon ride, at least some of the details that they have imagined should clash with details in the photo. "That's odd," they might think, "the balloon I remember was a different shape from what's in the photo." These inconsistencies should prompt people to evaluate their mental imagery more rigorously, and when they do, they may realize that they do not recall what happened before the balloon ride or how odd it is that the event was never the stuff of family stories. Ultimately they may reject the false event because their memory of the balloon ride does not meet the criteria for a genuine memory. But this process should occur only for description-first people, not photo-first people.

In short, theoretical reasoning about anchoring and consistency leads to different predictions about how the order in which people see written and photographic evidence of a false event might influence memories for it. We examined this issue in the following experiment.

\section{METHOD}

\section{Subjects}

Each of 53 confederate students from Victoria University of Wellington (New Zealand) and Warwick University (U.K.) recruited a family member, 18-30 years of age, whom they were confident had not experienced the false event. ${ }^{2}$ Each confederate and subject received a $\$ 25$ voucher (NZ) or $£ 15$ cash (U.K.).

\section{Design}

We used a two-group between-subjects design, with order (description-first, photo-first) as the factor, and we randomly allocated subjects to either the description-first condition $(n=27$, $59 \%$ female; $M=21.2$ years, $S D=3.6$ ) or the photo-first condition $(n=26,62 \%$ female; $M=21.7$ years, $S D=3.2)$. There were similar proportions of New Zealand and British subjects in the two conditions.

\section{Materials and Procedure}

For each subject, we created two booklets, following the format in Figure 1; one contained four photos of childhood events, and the other contained four descriptions of the same childhood events. Events 1, 2, and 4 were real; Event 3 was always the false event, a hot air balloon ride (Strange, Hayne, \& Garry, 2007; Wade et al., 2002). We verified with family members that the ride (which would have required parental consent) never happened.

Photo booklets. The confederates provided photographs of moderately significant events (school functions, family trips, celebrations) showing their family member (the subject) when he or she was 4-8 years of age. We asked the confederates to select a range of experiences, avoiding often-repeated events. We digitized the photos, cropped them to $15 \times 10 \mathrm{~cm}$, and printed them in grayscale at $300 \mathrm{dpi}$. We used Adobe Photoshop to produce the doctored image of the subject taking a balloon ride with at least one family member; Figure 2 shows an example.

Description booklets. For each real photo, the confederates described the event, the year it happened, the subject's age, and the people involved. For the false photo, we personalized a generic 45- 

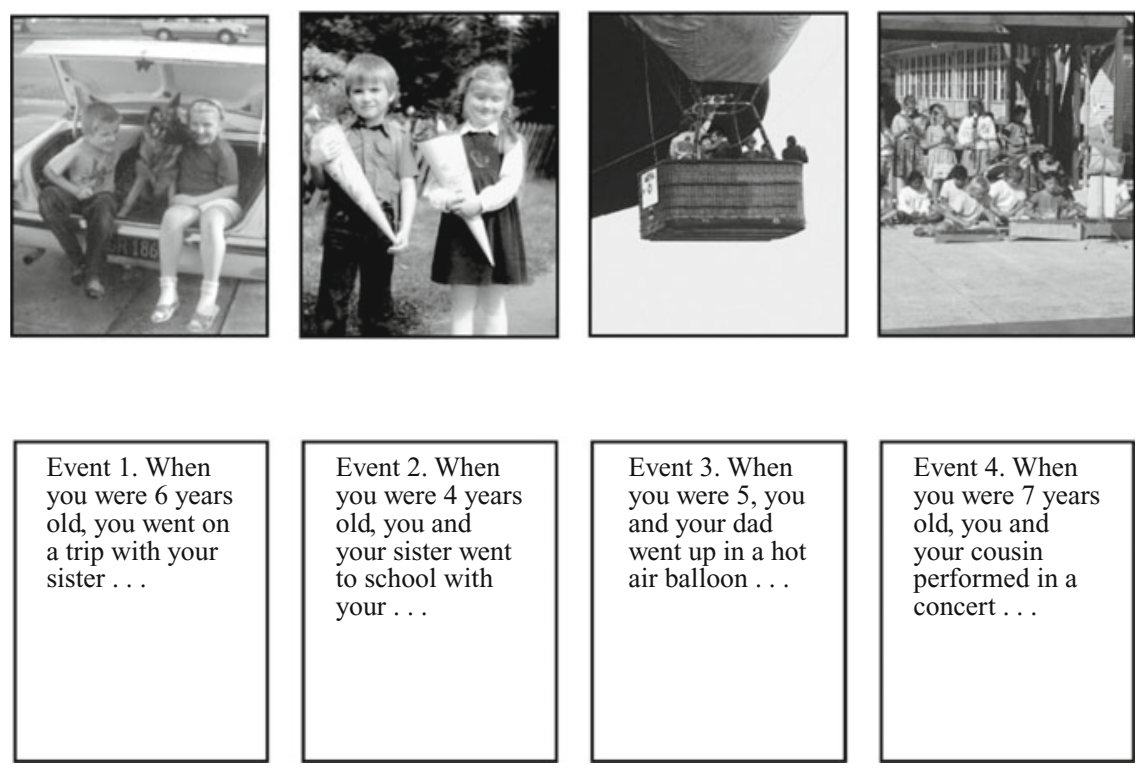

Figure 1. Sample of a photograph booklet (upper row) and description booklet (lower row).

word description, based on details in the photo and used in earlier research: "When you were around [6-8] years old, you and your [dad/mum/sister] went up in a hot air balloon. You didn't go far off the ground because the ropes anchoring the balloon were still attached" (Garry \& Wade, 2005, p. 360).

Interviews. We used Wade et al.'s (2002) procedure, interviewing people individually three times over 1 week. All the interviews were recorded.

Interview 1 . We told the subjects that the aim of the study was to investigate how people reminisce about childhood events. We gave the subjects Booklet 1, the format of which depended on their order condition, asked them to report everything they could recall about each event in turn, and reassured them that people often find it difficult to remember long-ago events. When the subjects had trouble recalling an event, we used guided imagery to encourage them to reinstate the physical and mental context of the event. Specifically, we asked them to concentrate on the description or photo for $1 \mathrm{~min}$, and to visualize the location, what they might have seen, and how they might have felt (Wade et al., 2002). We did not introduce any additional false information during this process. When the subjects could recall no more, we moved on to the next event.

We asked the subjects not to discuss childhood events with family members or to review other childhood photos until the study was over. They took a copy of their event booklet home to think about the events daily.

Interview 2. The second interview occurred 3-4 days later, depending on the subjects' availability. As they returned Booklet 1 , we told the subjects "sometimes thinking about childhood events in different ways can make a difference," and gave them Booklet 2 in the different evidence format. We then asked them to look at each

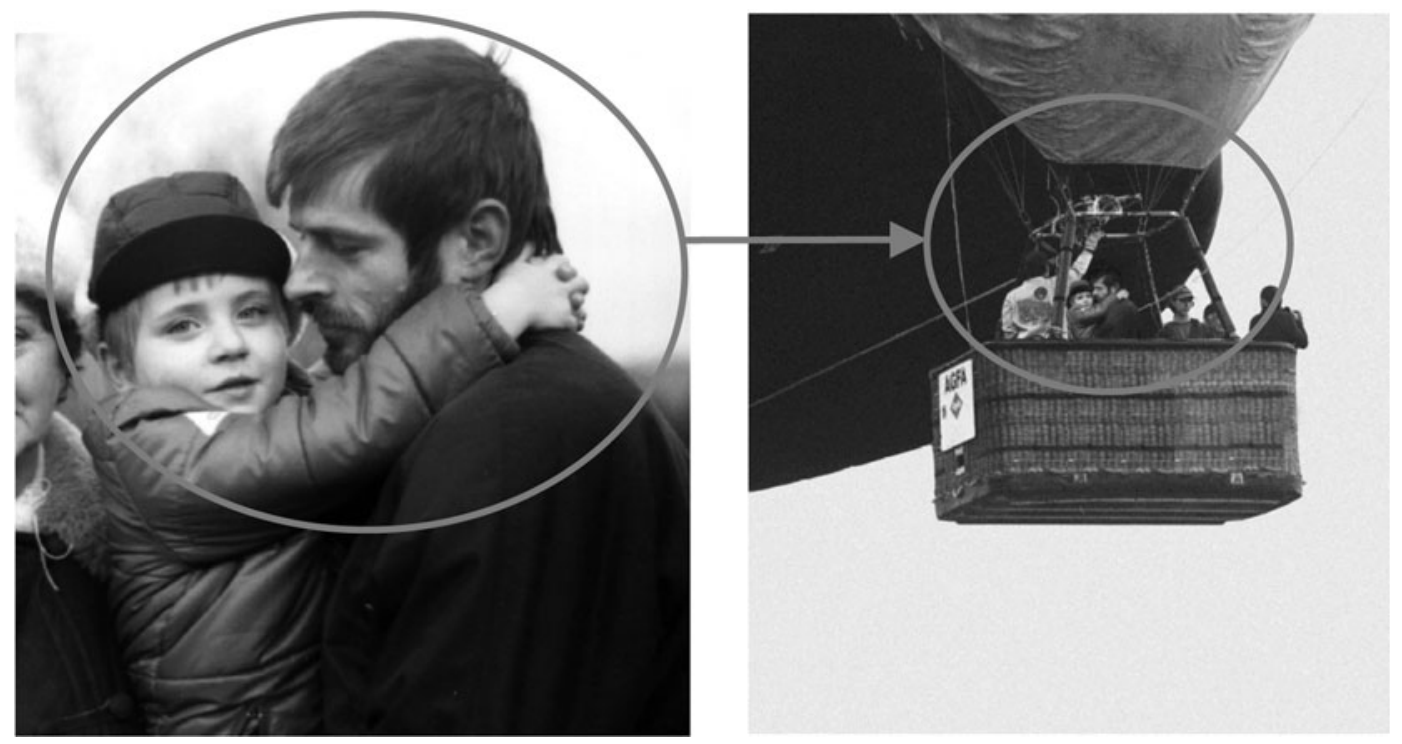

Figure 2. Process of doctoring a photo: Original photo provided by family confederate (left) and doctored photo (right). 


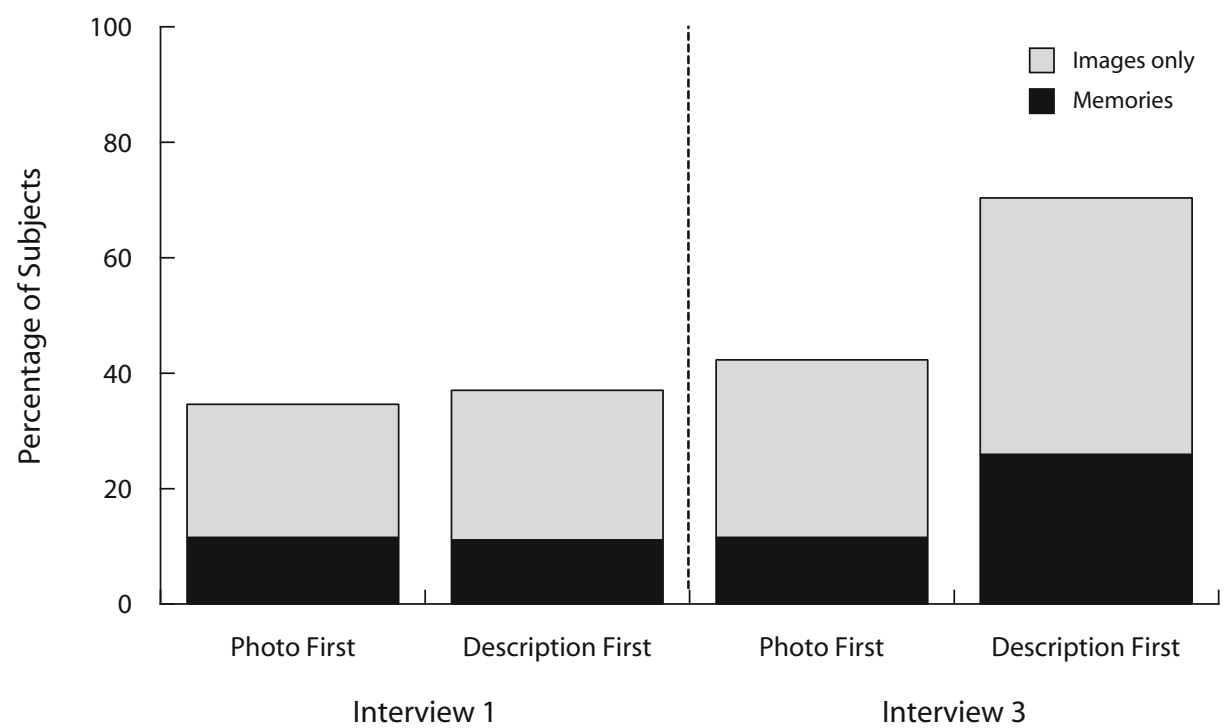

Figure 3. Percentages of subjects classified as having false images or memories as a function of condition and interview.

event in their second booklet and to report any additional details they could recall, rather than repeating details from Interview 1. For the false event and any true event that the subjects struggled to recall, we repeated the guided imagery instructions from Interview 1. Finally, we reminded the subjects not to discuss childhood events with family members or to review other photos. They took a copy of Booklet 2 home so that they could think about the events daily.

Interview 3. The final interview took place 1 week after Interview 1 and followed the same procedure, except that the subjects did not engage in guided imagery and they reported everything they could remember without a booklet in front of them. Before debriefing, we asked the subjects how often they had thought about the events during the study and whether they had discussed the events with others.

\section{RESULTS AND DISCUSSION}

Most of the subjects indicated surprise that one of the photos was a fake: "Really?" "That's awesome!" Moreover, two trained judges ${ }^{3}$ independently reviewed transcripts of the subjects' event reports to answer the question, "To what extent does the subject believe they took a childhood balloon ride?" (1 = strong disbelief; 5 = strong belief $)$. Judges concurred on $72 \%(\kappa=.80)$ of the categorizations and classified disputed cases into the more conservative category. In total, $83 \%$ of the subjects were judged to have a moderate or strong belief ( 4 or 5 on the scale). Together,

Table 1

Sample False Images and Memories

\begin{tabular}{|c|c|}
\hline Condition & Memories \\
\hline escription first & $\begin{array}{l}\text { Okay. Um, in this I remember um looking up and seeing the } \\
\text { flame; a big flame went up into the balloon. That was pretty } \\
\text { cool at the time. And the heat, I remember feeling the heat as } \\
\text { well, of the flame. And looking up and seeing the dude um } \\
\text { with the, pulling the thing that made the flame go up. And } \\
\text { um, he was wearing gloves too. And yeah. Um, my sister was } \\
\text { there and my mum was there, were there. }\end{array}$ \\
\hline
\end{tabular}

I think we'd gone to: we were having like a family day or something, some kind of family outing. It wasn't like we were just driving along in the car and we just saw a hot air balloon. I think we planned it. We sort of used to plan to have these family days. Um, I think we had a picnic as well. And then we went on the hot air balloon. We went on the hot air balloon at the end of the picnic. We had the picnic in a park or something ... I remember being really scared of the balloon guy, the actual driver. He was just a scary guy. I don't know, I can't remember any reason why I was scared but um, he just scared me. I think he was a pretty hard, hardened looking dude. He was a friendly, smiley type you know ... Just looking at his clothing just reminded me I was really scared of that guy for some reason. I don't know why. But you know. Just thought he was really scary. 
these findings suggest that the subjects were unaware of the true nature of the study and that our data were not the result of their trying to please the experimenter.

\section{Reports of the False Event}

We now turn to our primary research question: Did the order in which the subjects viewed the description and photo influence false recall? To answer this question, two new independent judges used Lindsay et al.'s (2004) criteria to determine who reported memories, images (but no memories), and no images or memories of the false event at Interview 1 and Interview 3 (judges did not score transcripts from Interview 2, because the subjects were not asked to provide extensive memory reports in that session). The subjects were classified as having a memory if they reported remembering the balloon ride, using terms such as "I remember ....," and reported details beyond those in the description or in the photograph. The subjects were classified as having images if they reported seeing mental images of the balloon, the people involved, or where it happened, but did not use terms that suggested that they were remembering the balloon ride. Judges concurred on $94 \%(\kappa=.90)$ of the categorizations at Interview 1 and $83 \%(\kappa=.77)$ at Interview 3 ; we classified disputed cases into the more conservative category.

As Figure 3 shows, by the end of the experiment, the description-first subjects were more likely to report false images or memories than were the photo-first subjects, a pattern that fits with the anchoring mechanism $\left[\chi^{2}(1, N=\right.$ $53)=4.31, p=.04, \phi=.59]$. Table 1 shows sample false reports. Note that no subject reported false information at Interview 1 prior to guided imagery.

Interestingly, the left panel in Figure 3 shows that the pattern of false reports at Interview 1 does not replicate the pattern Garry and Wade (2005) found at Interview 1, where descriptions elicited more false details than photos did. There are two methodological changes that could account for the difference in findings. First, Garry and Wade's false descriptions contained more self-relevant detail: the name of the subject's hometown. Because selfrelevant details can encourage false memories, Garry and Wade's false descriptions might have enhanced processing fluency more than did our descriptions. An enhancement in fluency might account for the difference in patterns (Desjardins \& Scoboria, 2007; Hyman et al., 1995). Second, Garry and Wade's event booklets contained a mix- ture of descriptions and photos, whereas our booklets contained all photos (photo-first subjects) or all descriptions (description-first subjects). Perhaps the subjective fluency of the false event is influenced by the subjective fluency of other, recently considered events. Garry and Wade proposed that descriptions enhance processing fluency more than do photos. If so, descriptions might be perceived as more fluent when presented alongside photos (as in Garry $\&$ Wade, 2005) than when presented alongside descriptions (as in this study). Such a mechanism would also account for the difference in patterns.

We did find differences between description-first and photo-first people's memory reports that fit with Garry and Wade's (2005) conclusion that descriptions give people carte blanche to imagine. Specifically, our two judges found a tendency at Interview 1 for description-first subjects to speculate more often (e.g., where the event occurred, who was involved, how they were feeling) than photofirst subjects $\left[M_{\text {Description-first }}=4.0\right.$ details $(S D=3.6)$ vs. $\left.M_{\text {Photo-first }}=2.5(S D=2.4) ; t(51)=1.80, p=.08\right]$.

At Interview 3, our two judges rated the extent to which the subjects believed the false event really had happened $(1=$ strong disbelief; $5=$ strong belief $)$. Overall, description-first subjects had stronger beliefs about the balloon ride than did photo-first subjects $\left[M_{\text {Description-first }}=\right.$ $4.1(S D=1.0)$ vs. $M_{\text {Photo-first }}=3.4(S D=1.3) ; t(52)=$ $42.44, p=.02]$, which perhaps is unsurprising, given that description-first subjects described more images and memories than did photo-first subjects. However, even when we examined only those subjects judged to have no images or memories, we found stronger beliefs among description-first subjects than among photo-first subjects $\left[M_{\text {Description-first }}=3.4(S D=0.9)\right.$ vs. $M_{\text {Photo-first }}=$ $2.5(S D=1.1) ; t(19)=2.17, p=.04]$. If descriptions give subjects more freedom to speculate and infuse personal knowledge, greater processing fluency might lead to stronger beliefs and more source-monitoring errors (Garry \& Wade, 2005; Lindsay, 2008).

\section{Characteristics of the False Reports}

Thus far, our data fit with an anchoring account of false memories. If this account were correct, we might also expect that, by the end of the study, description-first subjects should report more false details traceable to the description than to the photo, whereas photo-first subjects should do the opposite. That is what we found. Two new judges

Table 2

Samples of Description-First Subjects' Comments About Discrepancies

Comments

My mum was scared of those kinds of things too, so if she could do it, then I'm sure I'd be ok. I probably felt safe her being there.

I remember that [the flame] being like real close or something . . . but then, on the other hand, it doesn't look like there's much fire there now so I might be imagining it.

I imagined the basket being a bit more, um, not quite so long.

When I remembered back to the event I thought the ropes came off the bottom.

When I imagined it, it was different to what it actually is [in the photo].

In my memory I thought the basket was a lot smaller and a lot shadier and more closed.

It looks like we were actually quite high up!

There are heaps of people in there! I don't remember that. 
parsed the subjects' false event reports into clauses (excluding irrelevant clauses and repetitions) and classified those clauses according to whether information could be traced back to the first medium, the second medium, both media, or neither medium. The judges concurred on $99 \%$ of the categorizations. In line with an anchoring account, there was a tendency for the subjects in both conditions to report more details that were consistent with the first medium than with the second medium $\left[M_{\text {first }}=0.35(S D=\right.$ $0.90), M_{\text {second }}=0.11(S D=0.38), F(1,102)=3.32, p=$ $\left..07, \eta_{\mathrm{p}}^{2}=.03\right]$.

With so much support for an anchoring account, should we conclude that consistency played no role in people's false memories? The answer depends on whether the subjects actually encountered inconsistencies between their internally generated details of the balloon event and the details depicted in the photo. To address this issue, we asked two new independent judges to determine how many subjects described at least one discrepancy between their own images or memories of the false event and the doctored photo. Judges concurred on $94 \%(\kappa=.85)$ of the categorizations, and they classified the disputed cases via discussion. Table 2 illustrates some of the subjects' comments.

Judges determined that $48 \%$ of the description-first subjects reported an inconsistency about the balloon ride, yet none of the photo-first subjects did so $\left[\chi^{2}(1, N=53)=\right.$ $16.6, p<.01, \phi=.56]$. Thus, as the consistency account predicts, the description-first, but not the photo-first, subjects experienced inconsistencies between their own mental products and the details in the doctored photo. Yet, the description-first people developed more false images and memories than did the photo-first people. Of the descriptionfirst subjects who reported inconsistencies, $23 \%$ reported false images and $46 \%$ reported false memories.

These results cause us to wonder why, even in the face of inconsistencies they noticed, so many description-first subjects reported something about the false event. We suspected a confirmatory bias: Once the subjects believed that the ride really had happened, they were more likely to search for-or generate - information consistent with that belief than information inconsistent with it (Nickerson, 1998). This finding might explain why some people develop and retain erroneous memories in the face of conflicting evidence (the case of Ronald Cotton is an excellent example; see www.pickingcottonbook.com).

Our results fit with an anchoring account, but an additional test of our conclusion would be to use a $2 \times 2$ between-subjects design, manipulating the false medium viewed first (photo or description) and the false medium viewed second (photo or description). Such a design would clarify whether the second medium contributes to false memory development at all.

One counterexplanation for our results is that the description-first people were more motivated to work at remembering the false event than were the photo-first people. However, both groups reported thinking about the false event a similar number of times $\left[M_{\text {Description-first }}=\right.$ 6.6 times $(S D=3.8)$ vs. $M_{\text {Photo-first }}=6.3(S D=4.0)$; $F<1]$. Thus, the idea that the description-first subjects worked harder at remembering cannot adequately explain our findings.

Our findings help to refine Mazzoni and Kirsch's (2002) metacognitive model of false memory construction. Their model posits that, in the absence of a clear memory, we might use external evidence - such as information gleaned from family members or personal photos (see also Wade \& Garry, 2005) - to determine whether an event really occurred. This process of evaluating information from various sources may, according to our results, involve more than simply summing up the available evidence. Situational factors, such as the order in which the evidence is considered, could play a significant part.

\section{AUTHOR NOTE}

We thank Claire Yaxley, Cathy Brown, Olwen Bryer, and Giles Poulter for their assistance. Correspondence concerning this article should be addressed to K. A.Wade, Psychology Department, University of Warwick, Coventry, CV4 7AL, England (e-mail: k.a.wade@warwick.ac.uk).

\section{REFERENCES}

Carlson, K. A., \& Russo, J. E. (2001). Biased interpretation of evidence by mock jurors. Journal of Experimental Psychology: Applied, 7, 91-103. doi:10.1037/1076-898X.7.2.91

Desjardins, T., \& Scoboria, A. (2007). "You and your best friend Suzy put Slime in Ms. Smollett's desk": Producing false memories with selfrelevant details. Psychonomic Bulletin \& Review, 14, 1090-1095.

Garry, M., \& Gerrie, M. P. (2005). When photographs create false memories. Current Directions in Psychological Science, 14, 321-325. doi:10.1111/j.0963-7214.2005.00390.x

GARRY, M., \& WADE, K. A. (2005). Actually, a picture is worth less than 45 words: Narratives produce more false memories than photographs do. Psychonomic Bulletin \& Review, 12, 359-366.

Hart, A. J. (1995). Naturally occurring expectation effects. Journal of Personality \& Social Psychology, 68, 109-115. doi:10.1037/0022 $-3514.68 .1 .109$

Hyman, I. E., JR., Husband, T. H., \& Billings, F. J. (1995). False memories of childhood experiences. Applied Cognitive Psychology, 9, 181-197. doi:10.1002/acp.2350090302

Johnson, M. K., Hashtroudi, S., \& Lindsay, D. S. (1993). Source monitoring. Psychological Bulletin, 114, 3-28. doi:10.1037/0033 $-2909.114 .1 .3$

Lindsay, D. S. (2008). Source monitoring. In J. Byrne (Series Ed.) \& H. L. Roediger III (Vol. Ed.), Learning and memory: A comprehensive reference Vol. 2: Cognitive psychology of memory (pp. 325-348). Oxford: Elsevier.

Lindsay, D. S., Hagen, L., Read, J. D., Wade, K. A., \& Garry, M. (2004). True photographs and false memories. Psychological Science, 15, 149-154. doi:10.1111/j.0956-7976.2004.01503002.x

Loftus, E. F. (2004). Memories of things unseen. Current Directions in Psychological Science, 13, 145-147. doi:10.1111/j.0963 -7214.2004.00294.x

Loftus, E. F., \& Pickrell, J. E. (1995). The formation of false memories. Psychiatric Annals, 25, 720-725.

Lyle, K. B., \& Johnson, M. K. (2006). Importing perceived features into false memories. Memory, 14, 197-213. doi:10.1080/ 09658210544000060

Mazzoni, G., \& Kirsch, I. (2002). Autobiographical memories and beliefs: A preliminary metacognitive model. In T. J. Perfect \& B. L. Schwartz (Eds.), Applied metacognition (pp. 121-146). Cambridge: Cambridge University Press.

McKinnon, M. (2008). Repair your life: A program for recovery from incest and childhood sexual abuse. Ann Arbor, MI: Loving Healing Press.

Nickerson, R. S. (1998). Confirmation bias: A ubiquitous phenomenon in many guises. Review of General Psychology, 2, 175-220. doi:10.1037/1089-2680.2.2.175

Ost, J., Foster, S., Costall, A., \& Bull, R. (2005). False reports of 
childhood events in appropriate interviews. Memory, 13, 700-710 doi:10.1080/09658210444000340

Peterson, C. R., \& DuCharme, W. M. (1967). A primacy effect in subjective probability revision. Journal of Experimental Psychology, 73, 61-65. doi: $10.1037 / \mathrm{h} 0024139$

PezdeK, K., Finger, K., \& Hodge, D. (1997). Planting false childhood memories: The role of event plausibility. Psychological Science, $\mathbf{8}$, 437-441. doi:10.1111/j.1467-9280.1997.tb00457.x

Porter, S., Yuille, J. C., \& Lehman, D. R. (1999). The nature of real, implanted and fabricated memories for emotional childhood events: Implications for the false memory debate. Law \& Human Behavior, 23, 517-538. doi:10.1023/A:1022344128649

Ross, M., Buehler, R., \& KARR, J. W. (1998). Assessing the accuracy of conflicting autobiographical memories. Memory \& Cognition, 26, 1233-1244.

SANDERSON, C. (2006). Counselling adult survivors of child sexual abuse (3rd ed.). London: Kingsley.

Sharman, S. J., \& Scoboria, A. (2009). Imagination equally influences false memories for high and low plausibility events. Applied Cognitive Psychology, 23, 813-827. doi:10.1002/acp.1515

Strange, D., Hayne, H., \& Garry, M. (2007). A photo, a suggestion, a false memory. Applied Cognitive Psychology, 22, 587-603. doi:10.1002/acp. 1390

WADE, K. A., \& GARRY, M. (2005). Strategies for verifying false autobiographical memories. American Journal of Psychology, 118, 587-602.
Wade, K. A., Garry, M., Read, J. D., \& LindSay, D. S. (2002). A picture is worth a thousand lies: Using false photographs to create false childhood memories. Psychonomic Bulletin \& Review, 9, 597-603.

Wade, K. A., Sharman, S. J., Garry, M., Memon, A., Mazzoni, G., Merckelbach, H., \& Loftus, E. F. (2007). False claims about false memory research. Consciousness \& Cognition, 16, 18-28. doi:10.1016/j.concog.2006.07.001

WHITFIELD, C. L. (1995). Memory and abuse: Remembering and healing the effects of trauma. Deerfield Beach, FL: Health Communications.

\section{NOTES}

1. $S D=20 \%$; range, $0 \%$ (Pezdek, Finger, \& Hodge, 1997) to $81 \%$ (Garry \& Wade, 2005)

2. We obtained similar patterns of results among our New Zealand and British samples.

3. Judges could not be blind to the order manipulation, because the subjects often referred to the format of the false evidence. However, all of our independent judges were first-year psychology majors in the first month of introductory psychology. They were naive with respect to our hypotheses and were unfamiliar with the false memory literature.

(Manuscript received June 17, 2009; revision accepted for publication September 27, 2009.) 